\title{
Junctural Alignment in Kyoto Japanese Compound Nouns
}

\author{
Andrew Angeles \\ University of California, Santa Cruz
}

\section{Introduction}

It has been observed in many languages that compound words show prosodic properties which are similar to but still different from prosodic properties observed in non-compound words. This can be observed especially in languages which exhibit a culminativity restriction, which requires that a lexical word have at most one syllable marked for the highest degree of metrical prominence, as defined in Hyman (2009). In such languages, even when the individual elements of a compound word have a syllable marked for the highest degree of metrical prominence, only one syllable may be so marked in a compound word. For example, a generalization about compound words in English is that they receive one primary stress on the first element of the compound, as in Chomsky and Halle's (1968) "Compound Rule," relegating the primary stress of the second element to the level of secondary, non-highest prominence, respecting culminativity, and yielding compounds such as ólive oil, from ólive and óil. ${ }^{1}$ While the single highest prominence in an English compound word is assigned to a syllable which also receives the primary stress when the compound member containing it occurs in isolation, this is not necessarily always the case across languages. In some languages, the location of highest prominence in a compound word may, in fact, not fall on any of the stressed syllables of the constituent words in isolation. Nespor and Vogel (1986) discuss the case of Greek, for example, which requires primary stress to fall on one of the last three syllables of the word. This restriction holds in both compound and non-compound words, though the actual location of stress is generally predictable in compound words, placing stress on one of the last three syllables, based on the vowel quality of the last vowel and morphological information. Observe in the following examples from Nespor and Vogel (1986); stress is indicated with an acute diacritic (e.g., á).

$$
\begin{aligned}
& \text { a. kúkla 'doll' + spiti 'house' = kuklóspito 'doll's house' } \\
& \text { b. níxta 'night' + puli 'bird' = nixtopúli 'night bird' }
\end{aligned}
$$

In (1a), primary stress falls on the antepenultimate syllable, the most common position of stress in compounds whose last vowel is a back vowel, whereas in (1b), primary stress falls on the penultimate syllable, the position on which stress tends to fall in compounds whose last vowel is a front vowel.

Such adherence to culminativity and the predictability of accent location is also found in Standard (Tokyo) Japanese compound accentuation. Since McCawley (1965), the standard view of compound accent location in Tokyo Japanese has been that the location of compound accent is predictable based on the length of the second element of a compound. The most basic generalization has been that compounds with "short," one to two mora first members place compound accent on the last syllable of the first element of the compound (henceforth "N1"), while compounds with "long," three to four mora second members place compound accent on the first syllable of the second element of the compound (henceforth "N2"). ${ }^{2}$ This is

\footnotetext{
* I would like to express my deepest appreciation to Ryan Bennett, Junko Ito, Jaye Padgett, and Haruo Kubozono for their comments, suggestions, support, and guidance in developing the work presented here. I would also like to thank the participants of the Phonetics and Phonology Lunch (Phlunch) and LarynxTime reading groups at UC Santa Cruz for their comments regarding previous versions of this work, as well as John Alderete, Eric Rosen, Donca Steriade, and Rachel Walker for their insightful comments and suggestions regarding the poster presentation of this work at AMP 2020.

${ }^{1}$ There are, of course, many exceptions. See for example Plag (2013) for discussion and references.

${ }^{2}$ Compounds whose N2s exceed four moras in length exhibit different behavior, which is beyond the scope of this paper and is not discussed here. For discussion, see Ito and Mester (2018) and references therein.
} 
shown in the examples below. Accent is marked by placing an apostrophe (') following the accented syllable, equivalent to the "accent corner" used in Japanese accent dictionaries. Except where otherwise noted, examples are from Hirayama (1960), Sugito (1995), Haraguchi (1999), and Nakai (2002).
a. kensetu 'construction' + syoo 'ministry' (2 moras $)=$ kensetu'-syoo 'Ministry of Construction' 3
b. sato 'village' + koko'ro 'heart' (3 moras) = sato-go 'koro 'homesickness' (Poser 1990)

A notable characteristic of Tokyo Japanese compound accentuation is that accent seems to cluster around the juncture between the two elements of the compound. In the case of (2a), the accented syllable occurs directly before the juncture, while in (2b), the accented syllable occurs directly after the juncture. This has led some scholars, such as Kubozono (1995), to posit that Tokyo Japanese compound accent must be aligned with the juncture. Recent work by Ito and Mester $(2018,2019)$ has shown, however, that Tokyo Japanese compound accent location can be accounted for without the need to invoke the notion of juncture.

Kyoto Japanese features a compound accentuation system that is very similar to that of Tokyo Japanese (Nakai 2002), with an important difference in what prosodic unit bears accent. In Tokyo Japanese, the accentbearing unit is the syllable, whereas, in Kyoto Japanese, the accent-bearing unit is the mora (Kubozono 2012). As a result, Tokyo Japanese allows accent to fall only on the heads of heavy syllables, whereas Kyoto Japanese allows accent to fall on either the head or the non-head of a heavy syllable. This results in differences in compound accent location in some cases, producing, for example, the following distinction:

a. Tokyo Japanese: ne'kutai 'necktie' + pi'n 'pin' = nekuta 'i-pin 'necktie pin' (Kubozono 1995)

b. Kyoto Japanese: ne'kutai 'necktie' + pi'n 'pin' = nekutai'-pin 'necktie pin' (Sugito 1995)

Tokyo Japanese compounds have compound accent which is not aligned with the juncture when N1 ends in a heavy syllable and N2 is short as in (3a) and compound accent which is aligned with the juncture in all other cases. Kyoto Japanese compound accent, on the other hand, is always aligned with the juncture, regardless of whether N1 ends in a light or a heavy syllable or whether N2 is short or long. With this as crucial evidence, I argue in this work that compounds in Kyoto Japanese in fact do require reference to the juncture between compound elements. Furthermore, I demonstrate that reference to the juncture is truly necessary, as no set of ALIGN family constraints is able to account for the facts of Kyoto Japanese compound accent placement. Accordingly, I argue that "juncture" must be a targetable object for alignment.

\section{Background}

Japanese $\mathrm{e}^{4}$ is commonly cited as a "pitch accent language," in which prosodic prominence is signaled by modulations in pitch. Accent in Japanese manifests as a fall from high pitch to low pitch. In this paper, I follow Ito and Mester (2018) in assuming a representation of accent in Japanese as an $\mathrm{H}^{*} \mathrm{~L}$ tonal complex, in which the accentual $\mathrm{H}^{*}$ is linked to the accented mora, and the following $\mathrm{L}$ is linked to the following mora, as in the illustrations below, from Ito and Mester (2018).
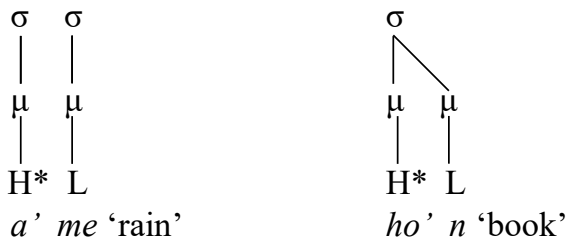

Japanese exhibits the culminativity restriction, but it does not exhibit obligatoriness, the requirement that a lexical word have at least one accent (Hyman 2009, Kubozono 2012). Thus, words in Japanese may have or

\footnotetext{
${ }^{3}$ Japanese compounds are indicated with a hyphen (-) between their members. Glosses are either my own or from Jim Breen's WWWJDIC http://nihongo.monash.edu/cgi-bin/wwwjdic.

${ }^{4}$ Where a distinction is not crucial, Tokyo Japanese and Kyoto Japanese are referred to collectively as "Japanese."
} 
lack an accent. In accented simplex words, accent location is generally unpredictable, although accent locations are not equally prevalent (e.g., the majority of accented three mora nouns have initial accent, although accent may in principle fall on any of the three moras) (Kubozono 2008). Accent location in compound words with $\mathrm{N} 2 \mathrm{~s}$, one to four moras in length, on the other hand, is largely predictable. The standard view for Tokyo Japanese, held since McCawley (1965), is that compounds with short, one to two mora N2s, are accented on the last syllable of N1, while compounds with long, three to four mora N2s, are accented on the first syllable of N2. Crucially, these generalizations hold regardless of whether the input constituents are accented or unaccented in isolation and, in the case of accented elements, regardless of the location of an element's isolation accent. Observe in the following examples.

$$
\begin{aligned}
& 1 \text { mora N2: } \\
& \text { a. sigoto 'work' + si' 'specialist' = sigoto'-si 'workman'5 } \\
& \text { b. kata'kuri 'dogtooth violet' + ko' powder' = katakuri'-ko 'dogtooth violet powder'6 } \\
& 2 \text { mora } \mathrm{N} 2: \\
& \text { c. abura 'oil' + musi 'insect' = abura'-musi 'aphid' } \\
& \text { d. ka 'buto 'helmet' + musi 'insect' = kabuto'-musi 'beetle' } \\
& 3 \text { mora N2: } \\
& \text { e. sakura 'cherry blossom' + hu'buki 'blizzard' = sakura-hu'buki 'blizzard of falling cherry } \\
& \text { blossoms' } \\
& \text { f. yama' 'mountain' + sakura 'cherry blossom' = yama-za'kura 'mountain cherry blossom' } \\
& 4 \text { mora N2: } \\
& \text { g. siritu 'private establishment' + daigaku 'university' = siritu-da'igaku 'private university' } \\
& \text { h. a'isu 'ice' + koohi'i 'coffee' = aisu-ko'ohii 'iced coffee' }
\end{aligned}
$$

As the examples above show, it does not matter whether $\mathrm{N} 1$ has an accent $(5 \mathrm{~b}, \mathrm{~d}, \mathrm{f}, \mathrm{h})$ or not $(5 \mathrm{a}, \mathrm{c}, \mathrm{e}, \mathrm{g})$, whether N2 has an accent (5a, b, e, h) or not (5c, d, f, g), or, in elements with accents, where that accent falls in isolation - initial (N1: 5d, h; N2: 5a, b, e), medial (N1: 5b; N2: 5h), or final (N1: 5f; N2: 5a, b). The only factor which matters in these examples is the length of N2, such that compounds with one to two mora N2s receive accent on the last syllable of N1, and compounds with three to four mora N2s receive accent on the first syllable of N2. Furthermore, note that compound accent is placed even when neither of the input elements has accent in isolation $(5 \mathrm{c}, \mathrm{g})$.

Treatments of compound accent placement in Tokyo Japanese have included Poser (1990)'s analysis of accent in compounds with long N2s with final foot extrametricality, Kubozono (1995)'s Optimality Theoretic analysis of both short and long compounds as an interaction of constraints requiring accent to fall on a nonfinal syllable which is in the rightmost, non-final foot and which is aligned with the juncture between members of a compound, and Ito and Mester $(2018,2019)$ 's Optimality Theoretic analysis of both short and long compounds as an interaction of constraints requiring accent to fall on the head of the rightmost, nonfinal foot in the head word, crucially without reference to the juncture.

An important characteristic of the Tokyo Japanese accent system is that, in accented words, both compound and non-compound, the accentual $\mathrm{H}^{*}$ may only fall on the head mora of a syllable (Kubozono 2012). Thus, accent may only fall on the lone mora of a light syllable or the first mora of a heavy syllable. This is particularly evident in loanwords three moras or longer, which are generally subject to an antepenultimate accent rule (Kubozono 2008), which places accent on the antepenultimate mora. If the antepenultimate mora is a non-head mora, e.g., the second mora of a long vowel, the moraic nasal, or the first half of a geminate, then accent is shifted leftward to the preantepenultimate mora, respecting the restriction that accent must fall on the head mora of a syllable, as illustrated below in examples from Vance (2008). In these examples, accent falls on the preantepenultimate head mora, be in (6a) and re in (6b), rather than on the following, antepenultimate non-head mora, $e$ (second half of the long vowel in the syllable bee) in (6a) or $k$ (first half of the geminate $k k$ ) in $(6 \mathrm{~b})$.

\footnotetext{
${ }^{5}$ Some monomoraic words, such as $s i$ ' 'specialist,' are accented. These, like longer final-accented words such as yama' 'mountain,' are indicated by placing an apostrophe (') after the sole mora in the word.

${ }^{6}$ Also kataku'ri-ko.
} 

a. erebe'etaa 'elevator'
*erebee'taa
b. konpure'kkusu 'complex'
*konpurek'kusu

The fact that accent always falls on a head mora is also observed in Tokyo Japanese compounds, when N1 ends in a heavy syllable and N2 is short. Thus, rather than placing compound accent on the non-head mora of the heavy syllable in perfect alignment with the juncture, compound accent is instead placed on the head mora of the heavy syllable, one mora separated from the juncture, as shown below.
a. yote'e-bi
'scheduled date'
*yotee'-bi
b. kyuude'n-bi
'electricity cut-off day'
*kyuuden'-bi

Kyoto Japanese has an accentual system which is similar to that of Tokyo Japanese - words may be accented or unaccented, compound words with short $\mathrm{N} 2 \mathrm{~s}$ receive compound accent at the end of N1, and compound words with long N2s receive compound accent at the beginning of N2 (Nakai 2002). ${ }^{7}$ Crucially, however, whereas Tokyo Japanese requires that accent fall on a head mora, Kyoto Japanese tolerates accent falling on either a head mora or a non-head mora in both compound and non-compound words (Kubozono 2012). Thus, in the following examples from Kubozono (2012), accent falls on a non-head mora: the moraic nasal $n$ in (8a) and the second part of a long vowel in (8b).
a. in'do
'India'
b. koo'tya
'black tea'

Kyoto Japanese loanwords are also subject to the antepenultimate accent rule (Tanaka 2018), but when the antepenultimate mora is a non-head mora, accent tends to shift to the preantepenultimate mora, as in Tokyo Japanese (Nakai 2002). Nonetheless, there are examples showing antepenultimate accent placement on a non-head mora, such as the following, from Sugito (1995).

$$
\text { konpurek'kusu 'complex' *konpure'kkusu }
$$

The availability of a non-head mora for accent placement in Kyoto Japanese results in a crucial difference between Tokyo Japanese and Kyoto Japanese in compound words with an N1 ending in a heavy syllable and a short N2. As discussed above, such compounds receive compound accent on the head mora of the last syllable of N1 in Tokyo Japanese. However, in Kyoto Japanese, accent is instead placed on the non-head mora, perfectly aligned with the juncture between compound elements (10a-d), shown below in a side-byside comparison with Tokyo Japanese, which places accent on the head mora, one mora before the juncture (10e-h).
Kyoto Japanese
a. yotee'-bi 'scheduled date'
Tokyo Japanese
b. kyuuden'-bi 'electricity cut-off date'
e. yote'e-bi
c. unten'-seki 'driver's seat'
f. kyuude'n-bi
d. nekutai'-pin 'necktie pin'
g. unte'n-seki
h. nekuta'i-pin

Thus, the dialects differ when accent would be placed on N1 and N1 ends in a heavy syllable. When accent would be placed on N2 and N2 begins with a heavy syllable, the two dialects are identical: both place compound accent on the head mora of the heavy syllable.

\footnotetext{
${ }^{7}$ In addition to accent, Kyoto Japanese words, both compound and non-compound, distinguish two word-initial tones, either high or low, which influence the overall tonal pattern of the word (Haraguchi 1999, Nakai 2002). These wordinitial tones do not play a role in the placement of compound accent and are thus not discussed here.
} 

a. kokuritu-da'igaku
'national university'
b. iro-e'npitu
'colored pencil'
c. minami-a'merika
'South America'
c. tegata-wa'ribiki
'discounting of a bill'

From these, then, the accentual systems can be generalized as follows. Tokyo Japanese always places accent on the head mora of a syllable. In compound words, accent is aligned with the juncture, except when the last syllable of N1 is heavy, and N2 is short, in which case, accent falls one mora before the juncture between elements instead. Kyoto Japanese, on the other hand, can place accent on a head mora or a non-head mora. In compound words, accent is always aligned with the juncture. Because of this fact, I argue that Kyoto Japanese is in fact targeting the juncture for alignment of the accentual $\mathrm{H}^{*}$. Consequently, I argue that a return to considering junctural alignment is necessary and that junctural alignment drives accent placement in both Kyoto Japanese and Tokyo Japanese compounds. In what follows, I first present an analysis of Kyoto Japanese with junctural alignment in section 3. In section 4, I consider whether reference to juncture and junctural alignment is truly necessary.

\section{A Return to Junctural Alignment}

In the previous section, we saw that when compound accent falls on N1, it falls as far to the right as possible, subject to whether a dialect requires accent to fall on a head mora or not. In Tokyo Japanese, accent falls on the head of the last syllable, whereas in Kyoto Japanese, accent falls on the last mora. When accent falls on N2, accent falls on the first mora of N2 in both dialects. Generalizing this further, the accentual $\mathrm{H}^{*}$ of the compound accent in Japanese is always immediately at or one mora away from the juncture between compound elements. From this, I propose that it must be possible for alignment to target the juncture and that juncture is indeed necessary to account for both Kyoto Japanese and Tokyo Japanese compound accent.

In this analysis, I assume the following syntactic structure for compounds, following Ito and Mester (in prep). Compounds are syntactic terminals $\mathrm{X}^{0}$, which consist of syntactic terminals $\mathrm{X}^{0}$.

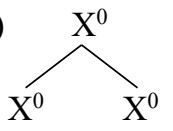

I assume a syntax-prosody mapping under Match Theory (Selkirk 2011), with the activity of a syntax-prosody mapping constraint $\mathrm{MATCH}\left(\mathrm{X}^{0}, \omega\right)$ interacting with a prosodic well-formedness constraint WORDBINARITY with the following definitions (Ito and Mester in prep).

a. $\operatorname{MAtch}\left(\mathrm{X}^{0}, \omega\right)$ : A terminal node $\mathrm{X}^{0}$ in the input must be matched with a prosodic word $\omega$ in the output, and both must dominate all and only the same elements.

Assign one violation for every terminal node $\mathrm{X}^{0}$ in the syntax such that the segments belonging to $\mathrm{X}^{0}$ are not all dominated by the same prosodic word $\omega$ in the input.

b. WORDBINARITY: A prosodic word $\omega$ must be binary.

Assign one violation for a prosodic word $\omega$ which measures no more than a single foot.

$\operatorname{MATCH}\left(\mathrm{X}^{0}, \omega\right)$ ensures that syntactic $\mathrm{X}^{0} \mathrm{~s}$ are mapped to prosodic words $\omega$ in the output, while WORDBINARITY ensures that a compound element measuring less than two feet is not mapped to a prosodic word $\omega$. I assume, following Ito and Mester (2018, in prep) that the differences in compound accentuation between compounds with short N2s and compounds with long N2s results from differences in the prosodic structures of these compounds. With WORDBINARITY dominating $\operatorname{MATCH}\left(\mathrm{X}^{0}, \omega\right)$, the interaction of these constraints will produce the following prosodic structures, a minimal word sister to a foot, which are daughters to a recursive maximal word in (14a) for compound words with short N2s, and two minimal words sister to each other, which are daughters to a recursive maximal word in (14b) for compound words with long $\mathrm{N} 2 \mathrm{~s}$. 
a.

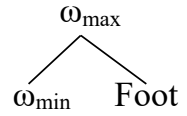

b.

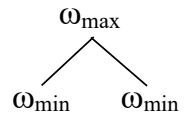

Constraint interactions are demonstrated in the tableaux below with kyuuden-bi 'electricity cut-off day' (15) representing compounds with short $\mathrm{N} 2 \mathrm{~s}$ and kokuritu-daigaku 'national university' (16) representing compounds with long N2s. In the tableaux below, the subscript abbreviation "Ft" is used to indicate feet.

Compound with short N2

\begin{tabular}{|c|c|c|}
\hline$/$ kyuuden\#hi/ & WORDBINARITY & MATCH $\left(\mathrm{X}^{0}, \omega\right)$ \\
\hline \multirow{\sigma}{*}{ a. $[\omega[\omega(\mathrm{kyuu})(\mathrm{den})][\mathrm{Ft}(\mathrm{bi})]]$} & & $*$ \\
\hline b. $[\omega[\omega(\mathrm{kyuu})(\mathrm{den})][\omega(\mathrm{bi})]]$ & $* ! \mathrm{W}$ & $\mathrm{L}$ \\
\hline
\end{tabular}

Compound with long N2

\begin{tabular}{|c|c|c|}
\hline kokuritu\#daigaku/ & WORDBINARITY & MATCH $\left(\mathrm{X}^{0}, \omega\right)$ \\
\hline a. $[\omega[\omega($ koku $)($ ritu $)][\mathrm{Ft}($ dai $)][\mathrm{Ft}(\mathrm{gaku})]]$ & & $* ! \mathrm{W}$ \\
\hline \multirow{2}{*}{ b. $[\omega[\omega(\mathrm{koku})(\mathrm{ritu})][\omega($ dai $)(\mathrm{gaku})]]$} & & \\
\hline
\end{tabular}

The candidate in (15b), with $b i$ 'day' projecting a prosodic word $\omega$ is eliminated because $b i$ consists of only a single foot, in violation of the WORDBINARITY requirement that prosodic words be binary. This constraint dominates $\operatorname{MATCH}\left(\mathrm{X}^{0}, \omega\right)$, which requires that $b i$ be nonetheless mapped to a prosodic word. As a result, the candidate in (15a) is selected as the optimal candidate. In (16), neither candidate violates WORDBINARITY, as daigaku is binary in (16b), and $\mathrm{N} 2$ is not contained within a prosodic word in (16a), and neither dai nor gaku project a prosodic word consisting of a single foot. $\operatorname{MATCH}\left(\mathrm{X}^{0}, \omega\right)$, then, determines the winner of this contest, (16b), as daigaku is not matched to a prosodic word in (16a), as the constraint demands.

Having discussed the mapping of the syntactic structure of compounds to their prosodic structures, let us now consider the analysis of compound accent placement. The central proposal of the present work is that junctural alignment is necessary to capture the compound accentual facts of Kyoto and Tokyo Japanese. This is stated in the following constraint.

Align-JunCtUREHIGH (ALIGN-JH): An accentual $\mathrm{H}^{*}$ tone must be aligned with the left or right edge of the juncture. Assign one violation for an accentual $\mathrm{H}^{*}$ tone which is not aligned with the left or right edge of the juncture.

This constraint participates in a grammar which also includes the following constraints, based on Ito and Mester $(2018,2019)$.

a. NONFinAlity(FoOT') (NFF'): The accented foot must not be final in the word. Assign one violation for a foot containing accent which is final in the word.

b. Align-RightHigh (ALIGN-RH): Align a high tone to the right edge of a maximal word. Assign one violation for every mora which intervenes between the right edge of a high tone and the right edge of a maximal word.

c. High-TO-SYLlableHEAD (HTOSHD): A high tone is linked to the head (left) mora of a syllable. Assign one violation for a high tone which is not linked to the head mora of a syllable.

d. WORDMAXACCENT (WMA): A maximal word [+maximal, -minimal] must have accent. Assign one violation for a maximal, non-minimal word which does not have accent. (Assumed unviolated) e. PARSE- $\mu$ : Every mora is parsed into a foot. Assign one violation for every mora which is not parsed into a foot. (Assumed unviolated). 
The combination of (18a) NONFinaLity(FOOT') and (18b) ALIGN-RightHigH ensures that accent falls as far to the right as possible as long as it does not fall in a word-final foot. (18c) HIGH-TO-SYLLABLEHEAD corresponds with the restriction that accent in Tokyo Japanese must fall on the head mora of a syllable. (18d) WORDMAXACCENT ensures that a compound receives compound accent, even when neither of its input elements have accent in isolation. Although unaccented compounds do exist (often due to N2 being a socalled "deaccenting morpheme," Kubozono 1995), these are outside the scope of the present discussion, which focuses only on accented compounds. This constraint is therefore assumed to be unviolated for the purposes of the present discussion. Finally, (18e), PARSE- $\mu$ ensures that every mora is parsed into a foot, under the assumption that a mora must be parsed into a foot in order to receive accent, crucial in particular for compounds with short N2s whose N1s have an odd number of moras, e.g., sakura'-bana 'cherry blossom flower;' sakura has three moras. This constraint is also assumed to be unviolated.

The grammar containing ALIGN-JUNCTUREHIGH in (17) and the other constraints given in (18) accounts for the compound accentual patterns of both Kyoto Japanese and Tokyo Japanese. The grammars differ in terms of their rankings of ALIGN-JunctUREHigh, ALIGN-RightHigh, and High-TO-SYLLABLEHEAD.

In the case of Kyoto Japanese, ALIGN-JUNCTUREHIGH is undominated, resulting in consistent alignment to the juncture. The grammar of Kyoto Japanese is given in the following Hasse diagram.

Kyoto Japanese grammar

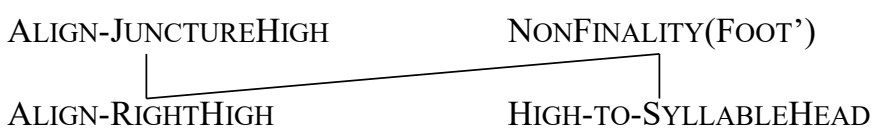

This grammar is demonstrated in the following tableaux.

In (20), four candidates are considered for minami-a'merika 'South America.' (20a) has junctural alignment of compound accent falling on the first mora of N2. (20b) has junctural alignment of compound accent falling on the last mora of N1. (20c, d) exhibit compound accent falling on a non-initial, non-junctural aligned mora in N2 - peninitial in (20c), penultimate in (20d). ALIGN-JUNCTUREHIGH ranked over ALIGNRigHTHIGH ensures that accent does not stray away from the juncture, eliminating (20c), which incurs one fewer violation of Align-RightHigh than does (20a). (20d) is eliminated by ALIGN-JuNCTUREHigh or NONFINALITY(FOOT'), as compound accent is simultaneously not aligned with the juncture and located in the final foot of the word. Finally, ALIGN-RightHigH ensures that compound accent does not stray too far away from the end of the word, selecting (20a) as the winner, with compound accent placed on the first mora of N2. HigH-TO-SYLLABLEHEAD is not relevant in this competition, but the case of compounds with short $\mathrm{N} 2 \mathrm{~s}$ demonstrates that it is relatively low ranked in Kyoto Japanese.

Kyoto Japanese compound with long N2

\begin{tabular}{|c|c|c|c|c|}
\hline /minami\#amerika/ & ALIGN-JH & NFF' & ALIGN-RH & HTOSHD \\
\hline a. (mina)(mi)-(a'me)(rika) & & & $* * *$ & \\
\hline b. (mina)(mi')-(ame)(rika) & & & $* * * *$ ! W & \\
\hline c. (mina)(mi)-(ame')(rika) & $* ! \mathrm{W}$ & & $* * \mathrm{~L}$ & \\
\hline d. (mina)(mi)-(ame)(ri'ka) & $* ! \mathrm{W}$ & $* ! \mathrm{W}$ & ${ }^{*} \mathrm{~L}$ & \\
\hline
\end{tabular}

Let us now turn to compounds with short N2s. In (21), three candidates are given for kyuuden'-bi 'electricity cut-off day.' (21a), which has junctural alignment of compound accent, falling on the non-head mora $n$ of the last syllable den of N1, (21b), which has junctural alignment of compound accent falling on N2, and (21c), which has compound accent falling on the head mora de of the last syllable den of N1. (21b) is eliminated by NONFinALITY(FOOT'), as it is accented on the last foot of the word. The contest in (20) demonstrated that ALIGN-JUNCTUREHIGH must be ranked above ALIGN-RIGHTHIGH in the grammar of Kyoto Japanese, so (21c) is eliminated by ALIGN-JunCTUREHIGH. (21) also demonstrates why HigH-TO-SYLLABLEHEAD must be ranked low. A higher ranking of this constraint would prefer either (21b) or (21c), depending on its ranking with respect to Align-JUnCTUREHIGH and NONFinAlity(FoOT'). 
Kyoto Japanese compound with short N2 and N1 ending in a heavy syllable

\begin{tabular}{|c|c|c|c|c|}
\hline /kyuuden\#hi/ & ALIGN-JH & NFF' & ALIGN-RH & HTOSHD \\
\hline a. (kyuu)(den')-(bi) & & & $*$ & $*$ \\
\hline b. (kyuu)(den)-(bi') & & $* ! \mathrm{W}$ & $\mathrm{L}$ & $\mathrm{L}$ \\
\hline c. (kyuu)(de'n)-(bi) & $* ! \mathrm{W}$ & & $* * \mathrm{~W}$ & $\mathrm{~L}$ \\
\hline
\end{tabular}

When N1 ends in a light syllable, and N2 is short, ALIGN-JUNCTUREHIGH again ensures that accent is placed on the last mora of N1, aligned with the juncture, as shown in (22). In (22), three candidates are considered for kensetu'-syoo 'Ministry of Construction.' (22a) has junctural accent on the last mora of N1, (22b) has junctural accent on the first mora of $\mathrm{N} 2$, and (22c) has non-junctural accent on the second-to-last mora of N1, parallel to (21c) above in that accent occurs one mora before the juncture. (22a), with accent immediately preceding the juncture, is once again selected as the winner. Because accent falls on the head (and only) mora of the syllable $t u$, no violation of HEAD-TO-SYLLABLEHEAD is incurred.

Kyoto Japanese compound with short N2 and N1 ending in a light syllable

\begin{tabular}{|c|c|c|c|c|}
\hline$/$ kensetu\#syoo/ & ALIGN-JH & NFF' & ALIGN-RH & HTOSHD \\
\hline a. (ken)(setu')-(syoo) & & & $* *$ & \\
\hline b. (ken)(setu)-(syo'o) & & $* ! \mathrm{W}$ & $* \mathrm{~L}$ & \\
\hline c. (ken)(se'tu)-(syoo) & $* ! \mathrm{W}$ & & $* * * \mathrm{~W}$ & \\
\hline
\end{tabular}

Reranking High-TO-SyllableHeAd and NonFinality(Foot') above Align-JunCtUREHigh while retaining the latter's ranking above ALIGN-RIGHTHIGH produces the grammar of Tokyo Japanese, as shown in the Hasse diagram in (23).

Tokyo Japanese grammar

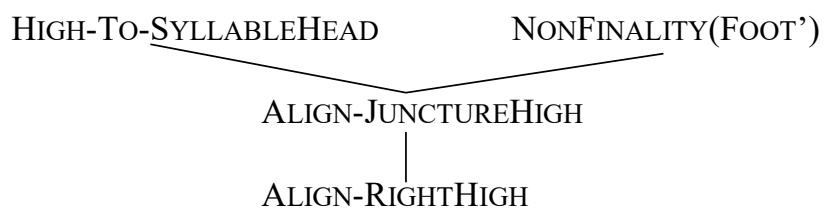

This grammar produces compound accentuation which is aligned with the juncture in all cases except when $\mathrm{N} 1$ ends in a heavy syllable, and N2 is short. This is demonstrated in the tableaux below, considering the same examples given above.

In (24), the candidate with compound accent on the first mora of N2 (24a) emerges as the winner. ALIGNJUNCTUREHIGH ensures that (22c) is not selected, as compound accent has strayed too far to the right. NONFINALITY(FOOT') eliminates (22d), which places compound accent in the final foot in the word. Finally, (22b) is eliminated by a compound accent which is too far away from the end of the word. Although it is not apparent in this contest, that NONFinAlity(FoOT') must be ranked above ALIGN-JUNCTUREHIGH is demonstrated in (25).

Tokyo Japanese compound with long N2

\begin{tabular}{|c|c|c|c|c|}
\hline /minami\#amerika/ & HTOSHD & NFF' & ALIGN-JH & ALIGN-RH \\
\hline a. (mina)(mi)-(a'me)(rika) & & & & $* * *$ \\
\hline b. (mina)(mi')-(ame)(rika) & & & & $* * * *$ W \\
\hline c. (mina)(mi)-(ame')(rika) & & & $* ! \mathrm{W}$ & $* * \mathrm{~L}$ \\
\hline d. (mina)(mi)-(ame)(ri'ka) & & $* ! \mathrm{W}$ & $* \mathrm{~W}$ & $* \mathrm{~L}$ \\
\hline
\end{tabular}


In (25), the candidate with compound accent one mora away from the juncture (25a) emerges as the winner. (25b) is eliminated because its accent falls in a final foot, while (25c) is eliminated because accent falls on the non-head mora of the final syllable den of N1. HEAD-TO-SYLLABLEHEAD ranked over ALIGNJUNCTUREHIGH ensures that junctural alignment does not occur when it would place accent on a non-head mora. Additionally, its ranking over ALIGN-RIGHTHIGH ensures that the head mora is preferred to a mora which is closer to the right edge of the word. NONFinality(FOOT') ranked over Align-JUnCTUREHigH ensures that the final foot does not receive accent, even though it is aligned with the juncture. Similarly, its ranking over ALIGN-RIGHTHIGH ensures that perfect alignment with the right edge of the word is not selected over avoidance of placing accent in the final foot.

Tokyo Japanese compound with short N2 and N1 ending in a heavy syllable

\begin{tabular}{|c|c|c|c|c|}
\hline /kyuuden\#hi/ & HTOSHD & NFF' & ALIGN-JH & ALIGN-RH \\
\hline a. (kyuu)(de'n)-(bi) & & & $*$ & * \\
\hline b. (kyuu)(den)-(bi') & & $* ! \mathrm{W}$ & $\mathrm{L}$ & L \\
\hline c. (kyuu)(den')-(bi) & $*$ ! W & & $\mathrm{L}$ & L \\
\hline
\end{tabular}

Finally, avoidance of placing compound accent on a non-head mora does not mean avoidance of placing accent on the second mora of a foot if that mora is co-extensive with a light syllable, as demonstrated in (26) below. Because $t u$ is the head mora of its syllable, no violation of HIGH-TO-SYLLABLEHEAD is incurred if compound accent is placed there as in (26a). NON-FINALITY(FOOT') eliminates (26b) for placing accent on the final foot. This again must dominate ALIGN-RIGHTHIGH, as avoidance of an accented final foot is more important than achieving a closer right alignment. ALIGN-JUNCTUREHIGH, determined to be ranked above ALIGN-RIGHTHIGH in (24), eliminates (26c) - the candidate parallel to (25a) in placing accent on the first mora of its foot - due to failure to align compound accent with the juncture. As (25) and (26), which both involve four mora N1s, show, accent is placed on the third mora when the fourth mora is the non-head mora of a heavy syllable; however, when the fourth mora is a light syllable (and thus the head and only mora of the syllable), compound accent is placed on the fourth mora. This results from the interaction of HIGH-TOSYllableHEAD with ALIGN-JunCtUREHigh, as shown in (25), or the lack thereof, as shown in (26).

Tokyo Japanese compound with short N2 and N1 ending in a light syllable

\begin{tabular}{|c|c|c|c|c|}
\hline /kensetu\#syoo/ & HTOSHD & NFF' & ALIGN-JH & ALIGN-RH \\
\hline a. $($ ken)(setu')-(syoo) & & & & $* *$ \\
\hline b. $($ ken)(setu)-(syo'o) & & $* ! \mathrm{W}$ & & $*$ L \\
\hline c. $($ ken)(se'tu)-(syoo) & & & $*$ ! W & $* * * \mathrm{~W}$ \\
\hline
\end{tabular}

Thus, juncture as a targetable object for alignment allows for the treatment of both Kyoto and Tokyo Japanese with the same constraints, in different rankings. ALIGN-JUNCTUREHIGH in both dialects causes compound accent to be aligned with the juncture between elements except where higher-ranked constraints in Tokyo Japanese prevent it from doing so in the case of compounds with heavy syllable-final N1s and short N2s. Its interaction with ALIGN-RIGHTHIGH and HIGH-TO-SYLLABLEHEAD produces the difference between dialects.

As a final comment on junctural accent, a natural question remains regarding the identity of the object representing "juncture." Ito and Mester (2019) propose that apparent junctural accent (as their analysis does not require reference to the juncture) in Tokyo Japanese occurs when the compound is a recursive word, as in (14) above. Given this, perhaps "juncture" is an edge of a minimal, non-maximal word ( $\left.\omega_{\min }\right)$. Whether this hypothesis is tenable remains to be investigated, and some possible avenues for investigation include other junctural phenomena, such as stop nasalization in Marathi, vowel lengthening in Hausa (see Vogel 2010 for brief discussion and references), or accentuation in certain compounds in Ancient Greek, which must occur adjacent to a compound boundary (Donca Steriade, p.c.). 


\section{Is Juncture Really Necessary?}

At this point, it is prudent to ask whether juncture as a targetable object for alignment is truly necessary for an account of Kyoto and Tokyo Japanese accent and beyond. The crucial evidence presented in favor of the present argument is that the dialects differ in how strictly compound accent must align with the juncture, where Kyoto Japanese requires it in all cases, and Tokyo Japanese requires it in all cases except where doing so would place accent on a non-head mora. Another characteristic of interest emerges when considering compounds with N1s with an even number of moras in light syllables combined with short N2s, as discussed in (22) and (26) above, and then comparing these with compounds with long N2s, in (20) and (24) above. To be noted here is that the dialects are inconsistent on whether it is the head or non-head mora of a foot that is to be accented, assuming trochaic feet as do Ito and Mester (2016) for Tokyo Japanese and Tanaka (2018) for Kyoto Japanese. Thus, in (27a), both dialects place compound accent on the non-head mora of the accented foot, while in (27b), both dialects place compound accent on the head mora of the accented foot. Only the relevant feet are marked.
a. $\operatorname{ken}\left(\right.$ setu' $\left.^{\prime}\right)$-syoo
'Ministry of Construction
b. kokuritu-(da'i)gaku
'national university'

The differences between the dialects regarding compounds with N1s ending in heavy syllables and short N2s as shown in (21) and (25) and the identical behavior of the dialects regarding the compounds in (27) suggest that these facts can be accounted for with different types of left and right alignment constraints.

Two main families of analysis seem to me to be plausible avenues for accounting for the two dialects without reference to juncture, given below. The spirit of each analysis is the same: to use general left- and right-edge alignment constraints, relativized to various levels of recursive word (maximal, minimal, any), and their interaction with each other and with the other constraints discussed above, excluding ALIGNJUNCTUREHIGH, to produce the correct output.

Two possible juncture-less analyses

a. Accent must fall as far to the right as possible, in a position aligned to the left edge of the prosodic word in which accent occurs.

b. Accent must fall as far to the left as possible, in a position aligned to the right edge of the prosodic word in which accent occurs.

While these seem initially plausible, an investigation with OTWorkplace (Prince, Tesar, and Merchant 2018) reveals that no combination of general left- and right-edge alignment constraints interacting with other relevant constraints can produce the correct outputs. Each analysis derives the correct accent location only for either, but not both, compounds with short N2s or compounds with long N2s. I discuss the details of this investigation and the results below.

To test these analytical families, I used three types each of Align-LeftHigh and AlignRightHigh constraints, relativized to 1) the maximal prosodic word, 2) the minimal prosodic word, or 3) any prosodic word, regardless of level. These constraints are defined below.

a. Align-LeFtHigh (ANYWord)/(MAXWord)/(MinWord): Align a high tone to the left edge of any word/a maximal word/a minimal word. Assign one violation for every mora which intervenes between the left edge of a high tone and the left edge of any word/a maximal word/a minimal word. b. Align-RightHigh (ANYWORD)/(MAXWORD)/(MinWORD): Align a high tone to the right edge of any word/a maximal word/a minimal word. Assign one violation for every mora which intervenes between the right edge of a high tone and the right edge of any word/a maximal word/a minimal word.

Given the difference in importance of HiGH-TO-SYLLABLEHEAD between the two dialects, it at first appears that the difference between the two dialects lies in the ranking of HIGH-TO-SYLLABLEHEAD and some combination of the constraints in (29). The constraints in (29) and the constraints in (18) above (except for 
PARSE- $\mu$, which was again assumed unviolated) were tested in OTWorkplace with the following candidates. Kyoto Japanese optima are marked with (K), Tokyo Japanese optima are marked with (T), and optima which are found in both Kyoto and Tokyo Japanese are marked with (KT).

$$
\text { OTWorkplace candidates }
$$

\begin{tabular}{|c|c|c|c|}
\hline$\frac{\text { 'engineering }}{\text { department' }}$ & 'scheduled date' & 'driver's seat' & 'Japanese spirit' \\
\hline ko'ogaku-bu & yo'tee-bi & u'nten-seki & ya'mato-gokoro \\
\hline kooga'ku-bu & yote'e-bi $(\mathrm{T})$ & unte'n-seki $(\mathrm{T})$ & yama'to-gokoro \\
\hline koogaku'-bu (KT) & yotee'-bi $(\mathrm{K})$ & unten'-seki (K) & yamato'-gokoro \\
\hline koogaku-bu' & yotee-bi' & unten-se'ki & yamato-go'koro (KT) \\
\hline koogaku-bu & yotee- $b i$ & unten-seki' & yamato-gokoro' \\
\hline & & unten-seki & yamato-gokoro \\
\hline 'private university' & 'electricity cut-off day' & $\frac{\text { 'Ministry of }}{\text { Construction' }}$ & 'South America' \\
\hline si'ritu-daigaku & kyu'uden-bi & ke'nsetu-syoo & mi'nami-amerika \\
\hline siri'tu-daigaku & kyuude'n-bi(T) & kense'tu-syoo & mina'mi-amerika \\
\hline siritu'-daigaku & kyuuden'-bi (K) & kensetu'-syoo (KT) & minami'-amerika \\
\hline siritu-da'igaku (KT) & kyuuden-bi' & kensetu-syo'o & minami-a'merika $(\mathrm{KT})$ \\
\hline siritu-dai'gaku & kyuuden-bi & kensetu-syoo' & minami-ame'rika \\
\hline siritu-daigaku' & & kensetu-syoo & minami-amerika' \\
\hline siritu-daigaku & & & minami-amerika \\
\hline
\end{tabular}

Violation counts for each candidate on each constraint tested were calculated and entered in OTWorkplace manually. A factorial typology was calculated in OTWorkplace, yielding 31 languages, of which one language was like Tokyo Japanese (Pseudo-Tokyo) in selecting all but one correct optimum, and one language was like Kyoto Japanese (Pseudo-Kyoto) in selecting all but two correct optima. None of the 31 languages was exactly Kyoto or Tokyo Japanese, and the remaining 29 languages fared worse than PseudoTokyo and Pseudo-Kyoto. The grammars of Pseudo-Tokyo and Pseudo-Kyoto generated by OTWorkplace are presented in the Hasse diagrams below. The names of the alignment constraints are shortened to "RAny/Max/Min" for the Align-RightHigh constraints and "L-Any/Max/Min" for the Align-LefTHigH constraints.

Pseudo-Tokyo Grammar

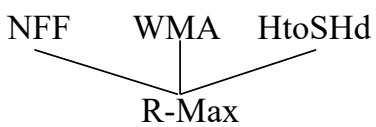<smiles></smiles>

Pseudo-Kyoto Grammar

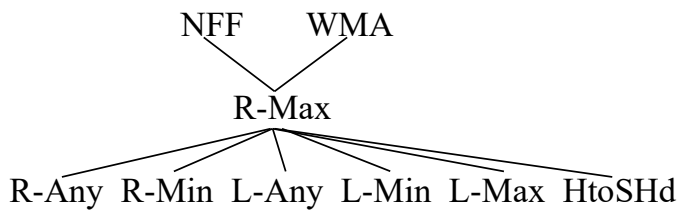

In Pseudo-Tokyo, NonFinality(Foot') and High-TO-SyllableHead are, expectedly, undominated, with both dominating ALIGN-RIGHTHIGH (MAXWORD) and the latter dominating all other alignment constraints. This is similar to the grammar proposed in the previous section in that the hierarchical relations between these three constraints are the same. This grammar is able to account for all of the (T) and (KT) forms in (30) except for minami-a'merika, which it incorrectly produces as minami-ame'rika instead. From the grammar, it is easy to see why: $m e$ is the rightmost mora which is neither in a final foot nor a non-head mora. None of the ALIGN-LEFTHIGH constraints are able to place the accent on $a$, where it belongs.

The issue with Pseudo-Kyoto is similar, with the relations between NonFinality(FoOT'), High-TOSyllableHeAD, and Align-RightHigh (MAXWord) once again identical to the relations proposed between these three constraints in the previous section. This grammar is able to account for all of the (K) and (KT) forms in (30) except for siritu-da'igaku, which it produces as siritu-dai'gaku, and minami-a'merika, 
which it produces as minami-ame'rika, like Pseudo-Tokyo. Once again, it is easy to see why: $i$ in siritudaigaku and me in minami-amerika are both the rightmost moras which are not in a final foot. The reason siritu-daigaku is incorrectly accented in Pseudo-Kyoto is because HIGH-TO-SYLLABLEHEAD is unable to ensure that the head mora $d a$ is accented instead.

Accordingly, I conclude that general left and right alignment are insufficient for accounting for Japanese compound accentuation and that junctural alignment is indeed necessary to derive the facts.

\section{Conclusion}

In this paper, I have shown that, although analyses which do not reference the juncture between compound elements are able to account for Tokyo Japanese compound accent placement, a crucial difference between Tokyo Japanese and Kyoto Japanese on whether accent must be placed on a head mora or not suggests that juncture as a targetable object for alignment is necessary to account for Kyoto Japanese and thus can be applied to Tokyo Japanese as well. Furthermore, invoking general alignment constraints to produce the junctural alignment effect appears to be insufficient as well, as shown by an investigation in OTWorkplace. Thus, juncture and junctural alignment are truly necessary for a theory of accent alignment.

\section{References}

Chomsky, Noam and Morris Halle. (1968). The Sound Pattern of English. New York: Harper \& Row, Publishers.

Haraguchi, Shosuke. (1999). Accent. In Natsuko Tsujimura (ed.) The Handbook of Japanese Linguistics, chapter 1, pp. 1-30. Malden, MA: Blackwell Publishers.

Hirayama, Teruo. (1960). Zenkoku Akusento Jiten [All-Japan Accent Dictionary]. Tokyo, Japan: Tōkyōdō Publishing.

Hyman, Larry M. (2009). How (not) to do phonological typology: the case of pitch accent. Language Sciences 31, pp. 213-238.

Ito, Junko and Armin Mester. (2016). Unaccentedness in Japanese. Linguistic Inquiry 47(3), pp. 471-526.

Ito, Junko and Armin Mester. (2018). Tonal alignment and preaccentuation. Journal of Japanese Linguistics, 34(2), pp. 195-222.

Ito, Junko and Armin Mester. (2019). Issues in recursive prosody. Presentation at NINJAL ICPP 2019, December 13-15, Tokyo, Japan.

Ito, Junko and Armin Mester. (in prep). Recursive Prosody and the Prosodic Form of Compounds.

Kubozono, Haruo. (1995). Constraint Interaction in Japanese Phonology: Evidence from Compound Accent. Phonology at Santa Cruz 4, pp. 21-38.

Kubozono, Haruo. (2008). Japanese accent. In Shigeru Miyagawa and Mamoru Saito (eds.), Handbook of Japanese Linguistics, pp. 165-191. Oxford, UK: Oxford University Press.

Kubozono, Haruo. (2012). Varieties of pitch accent systems in Japanese. Lingua 122(13), pp. 1395-1414.

McCawley, James D. (1965). The Accentual System of Standard Japanese. Massachusetts Institute of Technology, doctoral dissertation.

Nakai, Yukihiko. (2002). Keihan-kei Akusento Jiten [Keihan-type Accent Dictionary]. Tokyo, Japan: Bensei Publishing. Nespor, Marina and Irene Vogel. (2007) [1986]. Prosodic Phonology. New York: Mouton de Gruyter.

Plag, Ingo. (2013). The variability of compound stress in English: structural, semantic, and analogical factors. English Language and Linguistics 10(1), pp. 143-172.

Poser, William. (1990). Evidence for Foot Structure in Japanese. Language 66, pp. 78-105.

Prince, Alan, Bruce Tesar, and Nazarré Merchant. (2018). OTWorkplace. https://sites.google.com/site/otworkplace/home.

Selkirk, Elisabeth. (2011). The Syntax-Phonology Interface. In John Goldsmith, Jason Riggle, and Alan C. L. Yu (eds.) The Handbook of Phonological Theory (Second edition). Malden, MA: Wiley-Blackwell.

Sugito, Miyoko. (1995). Ōsaka Tōkyō Akusento Onsei Jiten [Osaka-Tokyo Accent Voice Dictionary]. Tokyo, Japan: Maruzen.

Tanaka, Yu. (2018). Accentuation in Tokyo and Kyoto Japanese: Toward a unified account. The $157^{\text {th }}$ Meeting of the Linguistic Society of Japan.

Vance, Timothy. (2008). The Sounds of Japanese. Cambridge: Cambridge University Press.

Vogel, Irene. (2010). The phonology of compounds. In Sergio Scalise and Irene Vogel. (eds.) Cross-Disciplinary Issues in Compounding. Philadelphia, PA: John Benjamins Publishing Company 